\title{
STUDIES ON CONIFEROUS TREE SEED AT THE UNIVERSITY OF BRITISH COLUMBIA ${ }^{1}$ \\ BY GEORGE S. ALLEN ${ }^{2}$ and WILLEM BIENTJES 3
}

\author{
ALLEN, G.S. \\ B.A.Sc. (For. Eng.) 1933, U.B.C. \\ M.A.Sc. (For Eng.) 1935, U.B.C. \\ Pb.D. (Boiany) 1945, California \\ Asst. Forester, B.C. F.S., 1938-45. \\ Instructor, Forestry, U.B.C. 1933-37. \\ Assoc. Prof., Forestry, U.B.C. 1945-47 \\ Professor, Forestry, U.B.C. 1947-53. \\ Dean, Faculty of Forestry, U.B.C. 1953. \\ Previous publications on seed germination and bebavior, seed production, \\ embryogeny, forest management and silviculture.
}

\section{BIENTIES W.}

Graduated in tropical forestry in 1949 from Landbouw Hoogeschool at Wageningen, Holland. After work in private forest management, be came to Canada and worked as a mill band, laborer, and research engineer. He began graduate work in forestry in September 1951 and completed course requirements for the M.F. in 1953. He should receive bis degree in May, 1954. His $M . F$. thesis will deal with germination requirements for bemlock seed.

\section{ABSTRACT}

There is a need for a reliable test for Douglas fir seed and seed of other important conifers. This paper describes a pretreatment and test for Douglas fir seed that provides reproducible results. Tests for seed of western bemlock, ponderosa pine, and the true firs are suggested that appear to have similar value. The pretreatment is a practical method that can also be applied in nursery practice; a preliminary test of this bas been carried out by the B.C. Forest Service and a summary of the results is given. A saving of nearly 40 per cent of seed for a given nursery production appears to be possible using this pretreatment as compared with the use of untreated seed. Preliminary results from seed storage studies are given for several coniferous species.

For the past five years, studies with coniferous seed have been conducted in the Faculty of Forestry, University of British Columbia. Limited funds and personnel have restricted the work to what might be called exploratory investigations. From these have come some findings of definite value, a

1 Research Paper No. 5, Faculty of Forestry, University of British Columbia, B.C. The work reported herein was made possible by grants provided by the President's Research Committee, University of British Columbia. Studies are continuing on tree seed quality control under a National Research Council Grant-in-Aid.

2 Professor of Silviculture and Dean, Faculty of Forestry, University of B.C.

3 Forest Scientist under a Grant from the National Research Council. 
number of promising leads, and some valuable experience. The findings and experiences that may be of interest to others are summarized in this paper. Emphasis to date has been on the development of a standard germination test as an essential starting point for other phases of seed research.

\section{Seed Research Problems}

Baldwin(2) has pointed to the many gaps that exist in our knowledge concerning forest tree seed. It is true that very little is known and that the field is wide open for valuable research. There are specific reasons why so little is known despite the fact that tree seed research began many decades ago. One reason is that many of the studies have been too empirical. Another related reason is that conclusions have too often been drawn from one or a very few collections or "lots" of seed. Rarely is a single "lot" of seed representative of the species. Seed behavior under conditions favorable to germination is often affected by factors not controllable by the investigator. Apparently conflicting results for the same species probably result from the variability caused by such factors. Seed research will not progress rapidly until optimum specifications for cone collection and handling, cone and seed processing, and cone and seed storage have been found. Then it will be possible to study seed that can be described as "normal", unaffected by artificial factors. Once the behavior of such seed is known, then abnormalities caused by factors such as premature cone collection, and unfavorable cone storage, processing, and seed storage, can be assessed. In other words, the test material must be controlled from start to finish; otherwise, results will be a heterogeneous collection of data relating to a heterogeneous population. This has probably been true of much of the tree seed research carried on in the past. Certainly this is true of the work herein reported, in part because of limitations of funds and personnel, and in part because of the difficulties of collecting suitable material during the recent poor seed years. On the other hand, in spite of the definite limitations of the work, the large amount of seed tested and the many replications have produced results that should be reliable.

\section{Objectives of Tree Seed Research}

Three specific objectives stand out above all others in immediate importance. These are:

(1) Quality control,-the development of the best possible methods of collecting, handling, and processing coniferous cones and seeds so that the highest yield of viable seed may be obtained from a cone collection,

(2) Storage, - the development of the best possible method of storing tree seed, during years of large crops, for use in years when little or no seed is produced, together with dependable data regarding storage losses to be expected over five or ten years under optimum storage conditions, and

(3) Testing, - the development of acceptable methods of testing each species that will give reproducible results. 
These three objectives may appear to be unrelated. Actually, the reverse is true. The assessment of the suitability of a particular method of processing the seed, or of a method of storing the seed, depends upon the use of a sensitive seed test. In a similar way, a storage method may appear to be unsatisfactory if the seed used has been maltreated during processing. The logical place to start is with the test. Once a satisfactory seed test has been found for a given species, the measuring device for evaluating processing, storage, etc., is at hand. The studies herein reported have been concerned mainly with test methods, particularly for Douglas fir, but to some extent for other species of commercial value. In addition, some storage trials have been undertaken, but these are limited by the use of seed lots with virtually unknown histories, and by the test methods used in assessing viability, particularly at the beginning of the study in 1949-50.

\section{Problems Involved in Germination Testing}

Superficially viewed, the testing of tree seed viability should present no serious difficulties. It should be possible to observe germination conditions in nature and then approximate these artificially. But, in the forest, coniferous seeds fall to the ground from about September until the following spring or early summer. They are exposed for varying lengths of time to high and low temperatures, to freezing and thawing, and to wetting and drying and, if all goes well, they germinate during the following spring or early summer. Under natural conditions, control of dormancy and of germination is probably related to temperature. But whether it is the average temperature, or the maximum, or the minimum or some other measure of heat level that is important, is not yet known. Laboratory experiments suggest that, as seed overwinters, it becomes less and less limited by temperature. Hence, conditions that permit germination in April, following several months of weathering, may be quite unfavorable for the germination of seed stored artificially over winter or longer, or of fresh seed when collected in September. This problem is solved, at least in part, by subjecting the seed to artificial overwintering or "stratification",- a period of moist cold treatment in the ground or in a refrigerator. Following stratification the seed of most coniferous species behaves more uniformly than it does when not treated.

It should be emphasized that the results of studies with untreated seed may have no validity when applied to the germination of seed in the field. Such results can be applied only to "untrcated" seed that does not occur in nature except when it first falls to the ground in the Autumn.

The problem of specifying an optimum germination procedure resolves itself into finding (a) the pretreatment, and (b) the germination conditions, that produce together the most rapid and most nearly complete germination. This is complicated by the fact that temperature requirements change progressively for seed as it receives longer and longer periods of stratification, within limits. It becomes a question of finding the best combination of pretreatment and germination conditions for the particular seed in question. Also there are the usual problems of sampling a given seed lot, of finding a test that suits all or a majority of seed lots with different histories, of deciding 


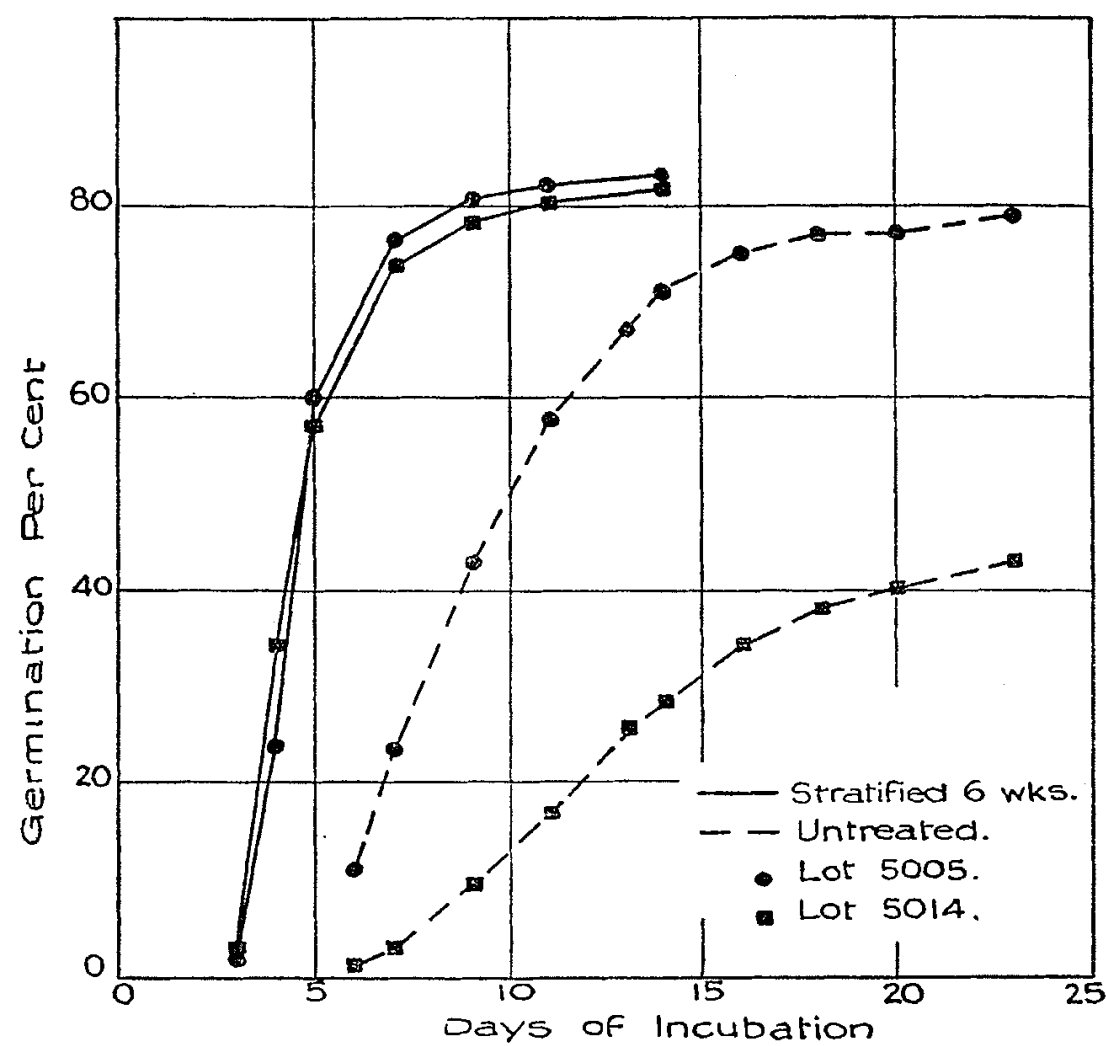

Figure 1. Course of germination of two lots of Douglas fir seed, one refractive (5014) and one much less so (5005), for untreared and stratified seed.

on the duration of the test, and so on. One fact stands out clearly, 一that a satisfactory test cannot be developed by experimentation with one or two lots of seed. Another is that most seed lots are heterogeneous and no procedure will result in the germination of all seeds at the same time. Only in the case of one species-Populus trichocarpa-has every seed germinated on the same day in this laboratory. Seeds of conifers are characterized by their individualistic germination behavior under even the most favorable conditions that have been provided.

Because most of the work in this laboratory has been with seed of Douglas fir, the following discussions will deal primarily with the testing of that species. 


\section{Testing Douglas Fir Seed}

A suitable test procedure for Douglas fir seed is badly needed. Considerable amounts of Douglas fir seed are exported to Europe and the local demand is increasing steadily. Whatever its end use, a value must be given to the seed in terms of its viability or of its ability to produce seedlings. As already stated, there is a real need to assess the methods used in processing cones and seed, and in storing seed, and a need for reliable information concerning losses during storage. Development of a standard test that will satisfy all of these requirements is essential if research is to lead to cheaper and better Douglas fir seed.

The seed of Douglas fir is not notoriously difficult to germinate and does not rank with seed of some of the white pines such as Pinus monticola and $P$. lambertiana. Nevertheless, it does give trouble as evidenced by the experience here and elsewhere in attempting to obtain reproducible values for a given lot of seed. For one thing, it is highly variable in its behavior. Seed from the continental climate east of the Coast Range responds well to ordinary germination techniques without special pretreatment. Seed from the milder Coast Region, on the other hand, varies from being reasonably responsive to the usual germination procedures to being nearly as "refractive" as seed of western white pine. The following sections refer to the coast type of Douglas fir seed.

\section{Pretreatment of Douglas Fir Selid}

Stratification, or cold moist treatment, has been used for many years to improve germination and to reduce the variability of germination behavior of Douglas fir seed under artificial or natural conditions $(1,2,3)$. Originally, the seed was mixed with sand and placed underground for a period of one month or longer $(1,3)$. More recently, in this laboratory, other methods have been tried. One convenient method used in testing germination consisted of placing the seed samples in filter paper envelopes, moistening in water, and storing in containers in the refrigerator for six weeks. This appeared to be as effective as stratification in sand or vermiculite and eliminated the need for scparating the seed from the medium prior to incubation. Another convenient method, used more recently, involves no medium. The seed is presoaked, then drained and surface-dried, and placed in containers in the refrigerator for a specified time. When the seed is taken from the refrigerator it can be immediately placed on the germination medium in the incubator or sown in the greenhouse or nursery.

To date the most satisfactory procedure for all lots of Douglas fir seed tested is as follows. The seed is presoaked in tap water for 24-30 hours at room temperature, reaching a moisture content (oven-dry basis) of 60 to 70 per cent. It is then surface-dried with paper towels until no damp spots show on dry paper, placed in appropriate containers with loose-fitting lids, and stored in the refrigerator at $0^{\circ}$ to $2^{\circ} \mathrm{C}$ for six weeks. Then the seed is placed in germination dishes and incubated at $25^{\circ} \mathrm{C}$. constant (see below under "medium", "temperature", etc.). 
Some lots of Douglas fir seed respond nearly as well to one week of stratification as to six weeks; these same lots germinate reasonably well without treatment (see Figures 1 and 2). But other lots that germinate slowly without pretreatment, require the longer period of stratification for best results (see Figure 2). It may be that the response to one week of stratification relative to that to six weeks is an indication of the seed's history; this may have diagnostic value in seed testing. Another point of interest is that the optimum temperature for germination is generally higher after one week of stratification than after six weeks.

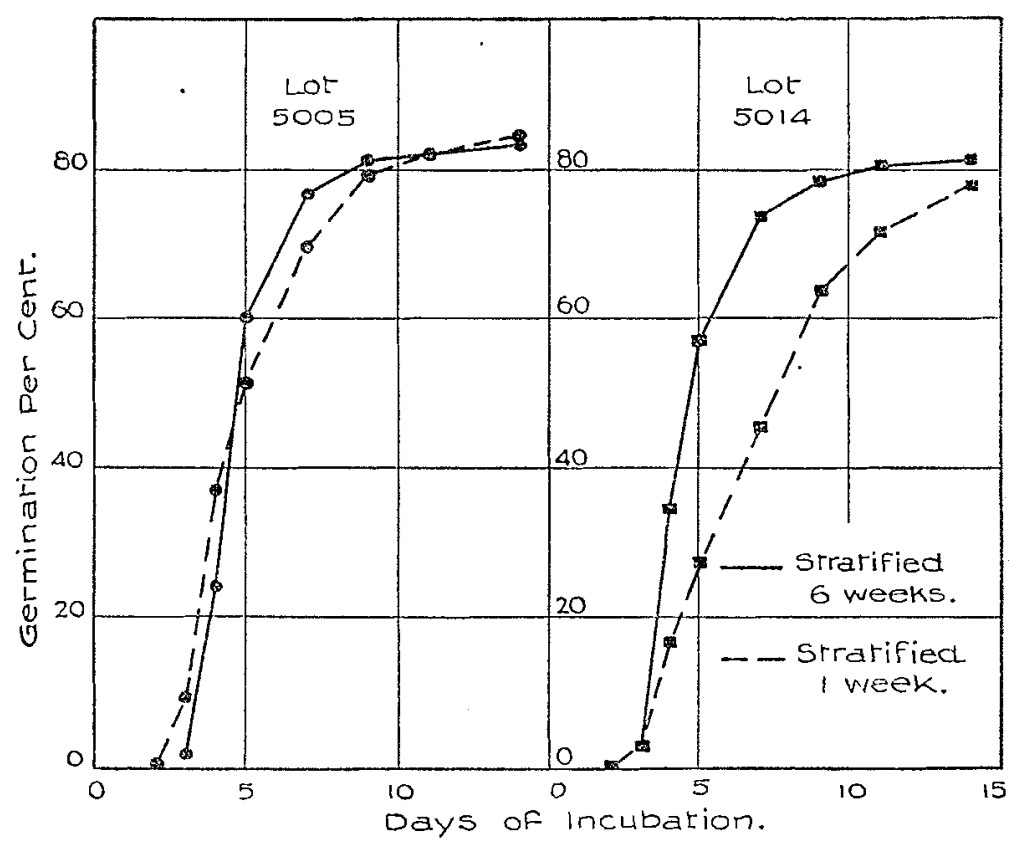

Figure 2. Differences in response to 1 and 6 weeks of stratification in a refractive lot of Douglas fir seed (5014) as compared with a much less refractive lot (5005), as snown by the course of germination following treatment.

Although artificial stratification is decidedly beneficial to Douglas fir seed, experience has shown that unusual variation among samples of the same seed lot may occur. Investigation has pointed to moisture content during stratification as the responsible factor, particularly in the case of stratification in filter paper envelopes. This difficulty is largely eliminated in the present technique 
in which no stratification medium is used. There is evidently an optimum range of moisture content, however, and best results to date have been obtained with an initial moisture content of between 60 and 70 per cent that drops to between 30 and 40 per cent after six weeks. There are practical limitations to the use of a constant moisture content since aeration must be provided; undoubtedly the optimum constant level would lie below 60 per cent since a sustained level of over 60 per cent has resulted in decreased germination. On the other hand, a gradually increasing moisture content from 8 or 10 per cent to about 70 per cent or higher during the refrigeration period (filter paper and vermiculite methods) has not been as satisfactory. It is likely that the present empirical method of maintaining a suitable moisture level during stratification can be improved.

In Table 1 are presented data that demonstrate, for two seed lots, the superiority of the "naked" stratification method with a presoaking period of 30 hours. Differences between stratification methods are generally significant but differences between six and eight weeks of pretreatment are not generally significant.

The course of germination for one lot of seed presoaked for 1,30 or 72 hours and stratified naked for six weeks is shown in Figure 3.

\section{TABLE 1}

Germination of two lots of Douglas fir seed following stratification of each by four different methods and for different presoaking periods in the case of naked stratification. (Averages based upon five replicates of 100 seeds each in each test)

\begin{tabular}{|c|c|c|c|c|c|c|c|c|}
\hline \multirow[b]{3}{*}{$\begin{array}{l}\text { STRATIFICATION } \\
\text { METHOD OF } \\
\end{array}$} & \multirow[b]{3}{*}{$\begin{array}{l}\text { Seedlot } \\
\text { No. }\end{array}$} & \multirow[b]{3}{*}{$\begin{array}{c}\text { Soaking } \\
\text { Period } \\
\text { Hours }\end{array}$} & \multicolumn{6}{|c|}{ Stratification Period } \\
\hline & & & \multicolumn{3}{|c|}{6 w eeks } & \multicolumn{3}{|c|}{8 weeks } \\
\hline & & & $\begin{array}{c}\text { Initial } \\
\text { m.c. } \\
\% \\
\end{array}$ & $\begin{array}{l}\text { m.c. } \\
\text { after } \\
\text { str'n } \\
\% \\
\end{array}$ & $\begin{array}{c}\text { Germ. } \\
\% \\
20 \text { days } \\
\end{array}$ & $\begin{array}{c}\text { Initial } \\
\text { m.c. } \\
\%\end{array}$ & $\begin{array}{c}\text { m.c. } \\
\text { after } \\
\text { Str'n } \\
\% \\
\end{array}$ & $\begin{array}{c}\text { Germ. } \\
\% \\
20 \text { daya } \\
\end{array}$ \\
\hline \multirow{4}{*}{$\begin{array}{l}\text { 1. Str } \\
\text { in } \\
\text { 2. Str } \\
\text { in } \\
\text { en }\end{array}$} & 5001 & - & 8.0 & 80.7 & 71.2 & - & - & - \\
\hline & 5004 & - & 8.0 & 62.4 & 83.2 & - & - & - \\
\hline & 5001 & - & 8.0 & 84.2 & 59.0 & - & - & $\ldots$ \\
\hline & 5004 & - & 8.0 & 69.7 & 83.8 & 一 & - & - \\
\hline \multirow{2}{*}{$\begin{array}{l}\text { 3. Naked stratifica- } \\
\text { tion without reser- } \\
\text { voir of moisture }\end{array}$} & 5001 & 30 & 71.2 & 34.2 & 81.4 & 71.2 & 23.5 & 80.3 \\
\hline & 5004 & 30 & 66.2 & 32.7 & 90.2 & 66.2 & 12.6 & 86.6 \\
\hline \multirow{6}{*}{$\begin{array}{l}\text { 4. Naked stratifica- } \\
\text { tion with reservoir } \\
\text { of moisture }\end{array}$} & 5001 & 4 & 42.0 & 33.1 & 74.0 & 42.0 & 39.8 & 67.4 \\
\hline & 5001 & 30 & 70.5 & 47.2 & 81.8 & 70.5 & 50.5 & 85.2 \\
\hline & 5001 & 72 & 80.3 & 58.4 & 74.4 & 80.3 & 65.9 & 77.4 \\
\hline & 5004 & 4 & 40.6 & 32.9 & 87.0 & 40.6 & 32.6 & 84.5 \\
\hline & 5004 & 30 & 65.8 & 48.7 & 88.2 & 65.8 & 41.5 & 89.8 \\
\hline & 5004 & 72 & 71.8 & 45.3 & 80.8 & 71.8 & 46.2 & 88.2 \\
\hline
\end{tabular}




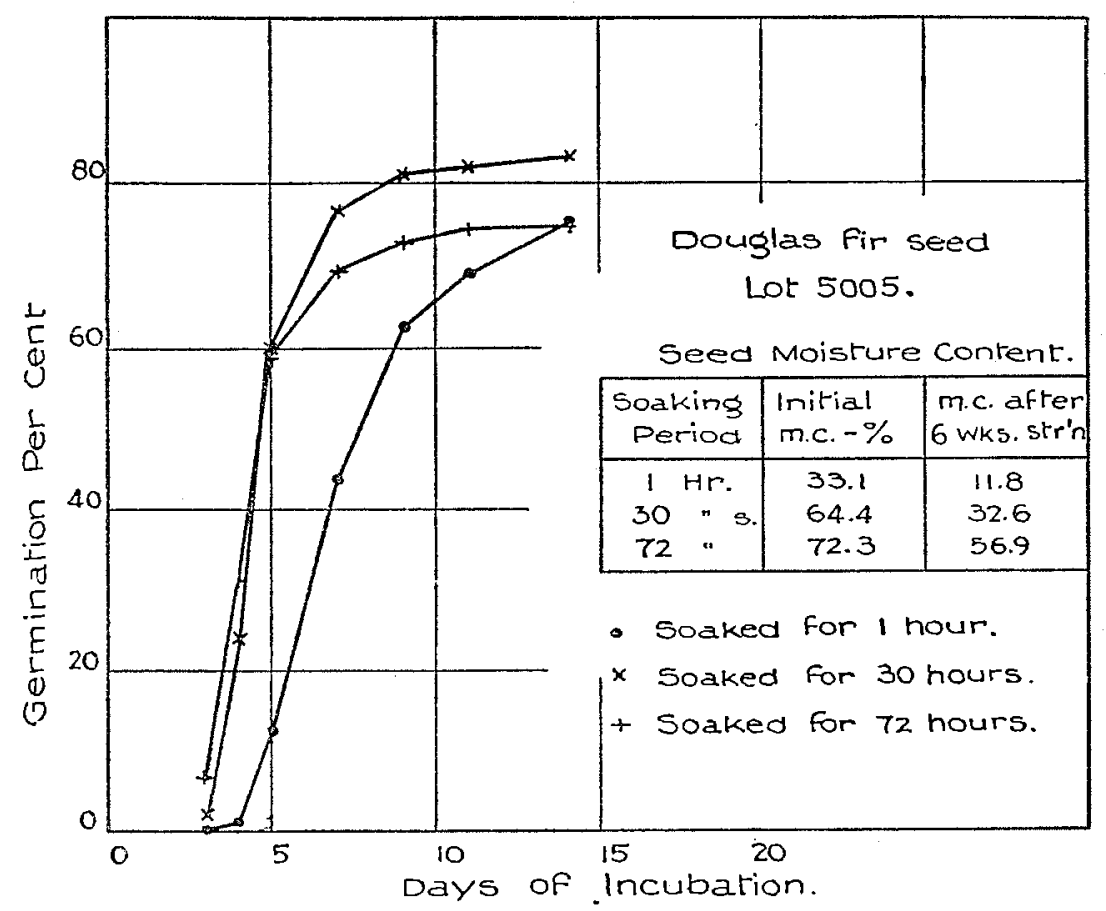

Figure 3. The effect of length of presoaking prior to naked stratification on the course of germination of Douglas Fir seed (lot 5005).

\section{Germination Temperatures for Douglas Fir Seed}

The most satisfactory germination temperature to date for stratified Douglas fir seed (six weeks at $0-2^{\circ} \mathrm{C}$.) has been $25^{\circ} \mathrm{C}$. constant. Here again, however, various seed lots exhibit differences that are consistent if not statistically significant for four to ten samples. Certain lots tend to respond slightly better to a lower constant temperature of about $20^{\circ} \mathrm{C}$. These are the lots that generally respond well to a shorter period of stratification (one week) with a higher incubation temperature $\left(25^{\circ} \mathrm{C}\right.$.). However, the differences between the values obtained for $20^{\circ} \mathrm{C}$ and $25^{\circ} \mathrm{C}$ are not important and, for all lots combined, the higher temperature is nearly always the better.

Some seed lots germinate better after one week of stratification when placed at $30^{\circ} \mathrm{C}$ for a few days and then at $25^{\circ} \mathrm{C}$ than they do at $25^{\circ} \mathrm{C}$ constant throughout. Yet, when these same lots are stratified for six weeks, there is no significant difference between results from the two temperature schedules. Again the modification of temperature effects caused by stratification is indicated. 
At temperatures of $30^{\circ} \mathrm{C}$ and higher the initial germination rate is often rapid, but it soon drops below that at $25^{\circ} \mathrm{C}$. Final germination per cent is generally lower for temperatures of $30^{\circ} \mathrm{C}$ and above than for $25^{\circ} \mathrm{C}$ constant, at least for stratified seed. Germination at an alternating temperature of $30^{\circ} \mathrm{C}$ maximum (eight hours daily), dropping to $15^{\circ}-20^{\circ} \mathrm{C}$ at night is essentially the same as that at $25^{\circ} \mathrm{C}$ constant. Germination at $25^{\circ}$ maximum, dropping to $15-20^{\circ} \mathrm{C}$ at night, is generally a little slower than at $25^{\circ} \mathrm{C}$ constant.

In general, for the many seed lots tested, the most satisfactory combination of pretreatment and germination temperature is $25^{\circ} \mathrm{C}$ constant following six weeks of stratification.

\section{GERMinAtion MEDia}

Many materials can be used as germination media but few are without serious drawbacks. The one selected and used consistently in this laboratory for several years is vermiculite (trade name "Terralite"). This material has many soil-like properties, holds moisture well, retains its porous structure long enough for the completion of a germination test and is not affected by microorganisms. Few other media have this last-named characteristic. In addition, vermiculite of a uniform quality is available at low cost in convenient amounts.

Vermiculite was chosen because of its sterile nature and for its ability to hold water and at the same time provide aeration. Incubators without humidity control have been used since this work began in this laboratory. Some means of maintaining a high relative humidity and conserving the moisture of the medium was required. To accomplish this, covered Petri dishes of an appropriate size were used, filled with vermiculite to within about $1 / 4$ inch from the tops. Water was added until the medium was saturated and the free water drained away. More recently, in an effort to obtain reproducible conditions, definite volumes of vermiculite and water were measured for the particular size of Petri dish used. The covered Petri dish with its supply of moist vermiculite is, in a sense, a micro-incubator within the larger chamber. Within it, relative humidity is maintained at very nearly 100 per cent.

Occasional lots of Douglas fir seed have been badly contaminated and have moulded seriously during incubation. A light dusting of "Arasan", using an atomizer or spray gun, reduces such fungal growth to a low level. Tests with Arasan, added at the time when the seed is placed in Petri dishes, have shown that the fungicide has no detectable effect upon germination.

The use of Petri dishes offers one means of obtaining reasonable uniformity of conditions in the type of incubator usually available for tree seed testing. One precaution must be taken, - that provision is made for aeration within the dish. Gaseous interchange may be facilitated by placing small bent chain links over the edges of the lower dish, separating the two dishes, or by drilling small holes in the upper dish; the latter method is used at the Oregon State Seed Testing Laboratory at Corvallis. If such precautions are not taken, a water seal may form and prevent aeration; experience has shown that this will usually result in lowered germination. 


\section{Duration of Test With Douglas Fir}

Many germination tests have been carried out in this laboratory on untreated Douglas fir seed. In some cases, germination was still taking place even after 150 days of incubation. Some seed lots can be tested without pretreatment in a period of 30 days or shorter. But for untreated seed there is no one length of test suitable for all seed lots. This is a very strong argument for the use of stratification in seed testing for this and other species.

Suitably stratified seed germinates rapidly and reaches the end of its "grand period" after about ten days of incubation at $25^{\circ} \mathrm{C}$ constant. Germination is virtually complete at the end of a total of 14 days. From this, "germinative energy" may be taken as the value obtained after ten days, and "total germination" as that after 14 days. On the other hand, seed stratified for only one week will reach its germinative energy value after 14 days and total germination at the end of about 21 days. These values are not as consistent as those obtained for seed stratified for six weeks, and the longer period of stratification is recommended because of its universal suitability and consistency of results.

Summary of Recommended Procedure for Testing Douglas Fir Seed

For the present the following procedure is recommended for whatever germination medium is used in the incubator.

(1) Soak the seed for 24-30 hours in tap water at room temperature, or until the seed moisture content is about 60 per cent (oven-dry basis).

(2) Drain the seed and dry with paper towels until no more damp spots appear on fresh towelling.

(3) Place surface-dried seed in loosely covered containers (glass preferably) in a refrigerator at $0-2^{\circ} \mathrm{C}$ for six weeks.

(4) Place samples on the germination medium, dust very lightly (dust barely visible) with Arason and incubate at $25^{\circ} \mathrm{C}$ constant (or alternating temperature of eight hours at $30^{\circ} \mathrm{C}$ and 16 hours at $15-20^{\circ} \mathrm{C}$ ).

(5) Count normal germinates and remove daily or bi-daily.

(6) Record "germinative energy" as the normal germination after ten days, and "total germination" as that after 14 days. In most cases, not more than 2 per cent will contain normal embryo and endosperm after 14 days of incubation.

This test measures satisfactorily the germinative power and capacity of nearly all seed lots. . Use of this procedure should help to reduce the discrepancies that are reported from time to time by seed dealers and others. The test procedure recommended does not reduce the need for proper sampling techniques that are essential for any reliable test.

Tentative Testing Procedures For Seed of Other Species

Considerable experience with certain other species indicates that the following test procedures are satisfactory and may serve tentatively until more intensive studies have been made. The procedures are similar to that given 
above for Douglas fir but details re soaking time, length of stratification, duration of test, and germination temperature differ. Details for Douglas fir are included for comparison.

\begin{tabular}{|c|c|c|c|c|c|}
\hline \multirow[t]{2}{*}{ Species } & \multicolumn{3}{|c|}{ Pretreatment } & \multicolumn{2}{|c|}{ Germination } \\
\hline & $\begin{array}{c}\text { Presoaking } \\
\text { Period- } \\
\text { Hours }\end{array}$ & $\begin{array}{c}\text { Str'n } \\
\text { Period- } \\
\text { Weeks }\end{array}$ & $\begin{array}{c}\text { Temper- } \\
\text { ature- } \\
\text { OC. }\end{array}$ & 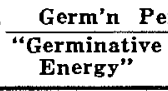 & $\begin{array}{c}\text { riod - days } \\
\text { "Total } \\
\text { Germination" }\end{array}$ \\
\hline $\begin{array}{l}\text { Western Hemlock } \\
\left(T_{\text {suga Heteropbylla }}\right.\end{array}$ & 36 hrs. & 8 whs. & $20^{\circ} \mathrm{C}$ & 14 days & 21 days \\
\hline $\begin{array}{l}\text { Ponderosa pine } \\
\text { (Pinus ponderosa) }\end{array}$ & $16 \mathrm{hrs}$. & 6 wks. & $25^{\circ} \mathrm{C}$ & 10 days & 14 days \\
\hline $\begin{array}{l}\text { Abies spp. } \\
\text { (nobilis, grandis) }\end{array}$ & $24-30$ hrs. & $6 \mathrm{wks}$ & $25^{\circ} \mathrm{C}$ & 10 days & 14 days \\
\hline $\begin{array}{l}\text { Douglas fir } \\
\text { (Pseudotsuga taxifolia) }\end{array}$ & $24-30$ hrs. & 6 wks. & $25^{\circ} \mathrm{C}$ & 10 days & 14 days \\
\hline
\end{tabular}

"Naked stratification" has not been tried extensively with other coniferous seed but good results thave been obtained for other species using filter-paper stratification. It is likely that similar schedules can be drawn up for other species, particularly the spruces, whose seeds respond well to a period of six weeks stratification and germination at $25^{\circ} \mathrm{C}$ constant.

\section{Preliminary Results for Seed Storage}

Studies to date have been rather crude because of limited refrigerator space. Although some of the results after three years of storage are contradictory, the general trends are fairly consistent. These trends are summarized below. Detailed results will be made available after five years of storage has been completed. All seed was stored in sealed vials under three temperature conditions-room, $0^{\circ} \mathrm{F}, 32^{\circ} \mathrm{F}$.

\section{Douglas fir (coast, 8 lots)}

Seed stored at room temperature lost viability steadily but 3 lots lost little or nothing in their first two years of storage. Moisture content of these was between 6 and 7 per cent. The greatest loss at room temperature was registered by a lot with moisture content of 9 per cent. Storage at $0^{\circ} \mathrm{F}$ and $32^{\circ} \mathrm{F}$ appear to be equally effective.

Western hemlock (coast, 3 lots)

Loss at room temperature was high but no serious or consistent losses have taken place at $0^{\circ} \mathrm{F}$ or $32^{\circ} \mathrm{F}$. Both cold storage temperatures appear to be satisfactory with a suggestion that $32^{\circ} \mathrm{F}$ is the better.

\section{Ponderosa pine (1 lot)}

Losses at room temperature were moderate but important $(20 \% \pm)$. At $32^{\circ} \mathrm{F}$ there was no significant loss but a considerable loss at $0^{\circ} \mathrm{F}$. This may be characteristic only of this one lot of seed. 
Lodgepole pine ( 1 lot) loss.

This seed was stored only at $32^{\circ} \mathrm{F}$ and kept well with no appreciable

Sitka spruce (2 lots)

One good lot maintained its viability at $0^{\circ} \mathrm{F}$ and $32^{\circ} \mathrm{F}$, but lost about $20 \%$ at room temperature. A poor lot showed a considerable loss under all three storage conditions.

White spruce ( 1 lot)

At $0^{\circ} \mathrm{F}$ there was no loss, at $32^{\circ} \mathrm{F}$ a 10 per cent loss, and at room temperature the loss was over 20 per cent.

Engelmann spruce (1 lot)

No loss was registered at $0^{\circ} \mathrm{F}$ or $32^{\circ} \mathrm{F}$ but viability dropped nearly $20 \%$ under room temperature storage.

Western red cedar ( 1 lot)

Almost no loss was recorded at $0^{\circ} \mathrm{F}$ but the seed stored very poorly at $32^{\circ} \mathrm{F}$ and at room temperature. An older lot of seed (1945 crop) stored with fairly low losses for more than five years at $32^{\circ} \mathrm{F}$ but unfortunately its original viability was not known accurately.

Port Orford cedar ( 1 lot)

Loss at $0^{\circ} \mathrm{F}$ and $32^{\circ} \mathrm{F}$ was less than 10 per cent over three years with no evident difference between results at the two temperatures.

White fir (Abies concolor, 1 lot)

Only a slight loss was shown at $0^{\circ} \mathrm{F}$ and $32^{\circ} \mathrm{F}$ but an almost complete loss at room temperature.

These results are of general value only. They come from run-of-the-mill seed rather than from seed processed under carefully controlled conditions. The information given above is not thoroughly reliable because germinaiton techniques had not been properly worked out when the storage study was started and because the test material itself was by no means ideal, although the best that could be obtained at the time. Reliable storage data will come only from very careful studies of ideally processed seed stored at several moisture contents under several storage temperatures. Such studies will be expensive in terms of labor and capital cost of equipment, but they are essential if the best use is to be made of the tree seed available during good seed years. It should be re-emphasized that storage studies, no matter how well designed and executed, will yield unreliable results unless the seed tests used give reproducible values consistently.

Application of Seed Pretreatment to Douglas fir Nursery Practice 4

In 1953 the British Columbia Forest Service undertook to test at the Duncan Nursery the effectiveness of "naked" stratification as developed in this laboratory. Although the method was tried in only a preliminary smallscale way, the results are worth recording. Three other pretreatments were included in the test together with a control. Treatments were as follows:

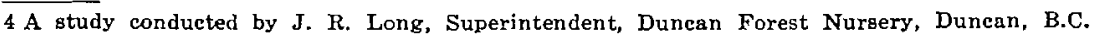


A. Seed soaked 30 hours at room temperature, surface dried, and placed in cold storage at $32^{\circ}-38^{\circ} \mathrm{F}$.

1. 10 days in cold storage

2. 15 days in cold storage

B. Dry seed placed in cold storage for 30 days at $0^{\circ} \mathrm{F}$.

C. Seed soaked and then sowed.

1. Soaked for 30 hours

2. Soaked for 48 hours

D. Seed stratified 30 days in moist peat.

E. Control. Dry seed, no treatment.

The amount of seed used for each seedbed was based upon the weight calculated to give 50 trees per square foot on the basis of a germination test and past experience. In the case of soaked seed, the amount required for each bed was weighed and placed in its own container. After soaking, the seed was spread out on canvas in the sun and stirred occasionally. Drying took about 15 minutes. The seed was then placed in glass jars with perforated lids in cold storage. No mold developed during storage.

Three seed beds $\left(4^{\prime} \times 50^{\prime}\right)$ were sown to seed receiving each treatment. Three permanent sample plots of three square feet each were established in each bed, giving nine plots for each treatment and a sample area of 27 square feet. Seed was sowed on May 14, 1953.

Table 2 shows the course of germination for the seven treatments in terms of number per square foot of seedbed.

TABLE 2

Cumulative germination of Douglas fir per square foot resulting from various seed pretreatments, Duncan Forest Nursery, Duncan, B.C., 1953.

\begin{tabular}{|c|c|c|c|c|c|c|c|}
\hline Treatment & June & June 15 & June 24 & $\begin{array}{r}\text { Date } \\
\text { July } 16\end{array}$ & Aug. 1 & Sept. 11 & $\begin{array}{c}\text { Total } \\
\text { Mortality } \\
\text { per sq. } \mathrm{ft} \text {. }\end{array}$ \\
\hline A1 & 8 & 43 & 55 & 58 & 65 & 68 & 2.4 \\
\hline A2 & 17 & 62 & 69 & 70 & 76 & 81 & 4.4 \\
\hline $\mathrm{B}$ & - & 9 & 19 & 35 & 64 & 67 & 2.0 \\
\hline $\mathrm{C}_{1}$ & - & 18 & 33 & 40 & 54 & 59 & 2.2 \\
\hline $\mathrm{C} 2$ & - & 19 & 34 & 41 & 58 & 61 & 1.7 \\
\hline . & 14 & 42 & 53 & 54 & 57 & 60 & 3.4 \\
\hline & & $\varepsilon$ & 8 & 27 & 46 & 51 & 1.0 \\
\hline
\end{tabular}

From these results the superiority of the longer period of "naked stratification (A2) seems evident, from the standpoints of both rate and amount of germination. It is possible that better results would be obtained from a longer period of stratification, at least in terms of rate of germination. As compared with the control "E", "A2" has produced about 60 per cent more seedlings from the same amount of seed. This represents a potential saving of 37.5 per cent in seed alone. In addition, seedling density should be more readily controlled; seedlings should be more uniform and more firmly estab- 
lished by the end of the first year. An additional important feature is that seedlings are given a more even chance, and culling is likely to eliminate the weak rather than those that are late to germinate. From a selection standpoint, uniformity of growing conditions and germination is very important.

These results confirm earlier findings (1) published in 1941. The important difference is that "naked" stratification is infinitely simpler and cheaper than stratification in sand or other medium that must be screened out at the end of the treatment. The naked seed takes up no more space when being stratified than when stored. Control of the seed's moisture content is definitely more straightforward than when a medium is used.

A considerably larger trial of this method of pretreatment is planned for 1954 at the Duncan Nursery by the British Columbia Forest Service.

\section{SUMMARY AND CONCLUSIONS}

Five years of exploratory research on the behaviour of coniferous seed has brought out clearly the wide variation that exists among seed lots of a single species. Conclusions based upon one or a few lots of seed may be misleading. Causes of the variation have not yet been determined with any certainty. They are likely related to heredity and to seed history - collection, handling, processing, and storage.

To date reasonably consistent test procedures for seed of Douglas fir (Coast) and western hemlock have been developed. These involve a pregermination treatment-stratification--that increases the rate of germination and reduces variation in behavior. The procedures being used result in germination of all but about 2 per cent of the filled seeds that live through the test. Preliminary studies with seed of other species suggest that similar procedures can be worked out successfully. Test procedures are necessary as the basis for other aspects of seed research such as storage and quality control. Experience suggests that the pretreatment may be relatively more important than the actual germination conditions, particularly when different lots of seed with varied histories are being tested. Given the optimum pretreatment, most seed lots will respond well to various germination temperatures. For the purpose of standardizing procedures, however, specific germination conditions are recommended following suitable pretreatments. It is hoped that these will be tried by other laboratories and used as standard if they prove satisfactory.

Preliminary seed storage studies have shown that, in sealed containers, seeds of a number of the western conifers will store well for at least three years at $0^{\circ} \mathrm{F}$ or $32^{\circ} \mathrm{F}$. Dependable information regarding seed storage must come, however, from considerably more intensive studies than have been possible to date in this laboratory.

\section{Literature Cited}

1. ALLEN, G. S. 1941. A standard germination test for Douglas fir seed. Forestry Chronicle $17: 75-78$.

2. BALDWIN, H. I. 1942. Forest Tree Seed. Chronica Botanica Company, Waltham, Mass.

3. MacDONALD, J. 1935. Nursery investigations. Forestry 9:24-41. 